\title{
Therapeutic hypothermia and outcome in hyponatraemic encephalopathy secondary to maternal water intoxication
}

\author{
Oluwaseyi Alake, ${ }^{1}$ Reena Rana, ${ }^{1}$ Anoo Jain, ${ }^{1}$ Ela Chakkarapani ${ }^{2}$
}

${ }^{1}$ Regional Neonatal Intensive Care Unit, University Hospitals Bristol and Weston NHS Foundation Trust, Bristol, UK ${ }^{2}$ Regional Neonatal Intensive Care Unit, St Michael's Hospital, University Hospitals Bristol and Weston NHS Foundation Trust, Bristol, UK

\section{Correspondence to}

Dr Ela Chakkarapani;

Ela.Chakkarapani@bristol.ac.uk

Accepted 28 February 2021

Check for updates

(c) BMJ Publishing Group Limited 2021. No commercial re-use. See rights and permissions. Published by BMJ.

To cite: Alake 0 , Rana $R$, Jain $\mathrm{A}$, et al. BMJ Case

Rep 2021;14:e237213.

doi:10.1136/bcr-2020-

237213

\section{SUMMARY}

Misguided encouragement to consume large volumes of water during labour for pain relief results in dilutional hyponatraemia in mothers and their babies presenting with neurological dysfunction. We report three babies who were encephalopathic with seizures in the background of hyponatraemia secondary to maternal ingestion of large volumes of water and mild perinatal asphyxia. All babies underwent therapeutic hypothermia in addition to sodium supplementation with fluid restriction. Their neurodevelopment was appropriate for age. This case series highlights the dilemma that could arise with hyponatraemic encephalopathy and mild perinatal asphyxia in the first 6 hours of life, which is the window of opportunity for therapeutic hypothermia for hypoxic-ischaemic encephalopathy. It is important to educate pregnant mothers in labour on the adverse effects of excessive fluid ingestion.

\section{BACKGROUND}

Seizures occur in 1-2 per 1000 term babies and result from several causes such as hypoxic ischaemic encephalopathy, intracranial bleed, metabolic derangements such as hypoglycaemia, hypocalcaemia and hyponatraemia. ${ }^{1}$ Dilutional hyponatraemia can occur in pregnant women during the intrapartum period, which can be hazardous as the fetus obtains water from the maternal circulation through the placenta. This leads to dilutional hyponatraemia in the fetus, triggering seizures after birth. ${ }^{2}$ We describe three infants with mild perinatal asphyxial encephalopathy and concomitant hyponatraemia secondary to maternal water intoxication who underwent therapeutic hypothermia $(\mathrm{TH})$ in addition to the treatment for hyponatraemia.

\section{CASE PRESENTATION}

\section{Case 1}

A term female infant was delivered via emergency caesarean section under general anaesthesia (GA) due to the mother having seizures during labour. The mother ingested $6 \mathrm{~L}$ of water during labour and was admitted to the intensive care unit with hyponatraemic seizures (sodium $108 \mathrm{mmol} / \mathrm{L}$ ) following delivery. The baby had mask continuous positive airway pressure (CPAP) support until 9 min of age and was floppy with a $10 \mathrm{~min}$ Apgar score of 8 . Arterial cord blood gas was acidotic with $\mathrm{pH} 7.033$, base excess (BE) -11 . She remained encephalopathic at 1 hour of age with absent gag and suck reflexes, starry gaze, hypotonia, small slowly reactive pupils and absent deep tendon reflexes. The amplitude integrated electroencephalogram (aEEG) showed a burst suppression pattern. Due to asphyxial encephalopathy, she was started on TH. Her blood gases showed respiratory acidosis with sodium 107 $\mathrm{mmol} / \mathrm{L}$ and she was intubated and ventilated. At 2 hours she had electro-clinical seizures which were treated with intravenous phenobarbital (20 $\mathrm{mg} / \mathrm{kg}$ ). She also received $2.7 \%$ hypertonic saline at $3 \mathrm{~mL} / \mathrm{kg}$ with maintenance sodium infusion at 5 $\mathrm{mmol} / \mathrm{kg} /$ day and fluids restricted to $40 \mathrm{~mL} / \mathrm{kg} /$ day. Other treatments included antibiotics for presumed meningitis and dopamine infusion for hypotension, which was stopped by day of life (DOL) 3. No pathogens were identified in the cerebrospinal fluid (CSF) and blood cultures. Her aEEG normalised by 48 hours and she was rewarmed after 72 hours cooling. On DOL 4 she was extubated, commenced on enteral feeds and sodium supplementation was stopped (table 1). Cranial ultrasound (CrUSS) suggested cerebral oedema with a resistance index of $0.43-0.56$. MRI brain, however, did not show any evidence of brain injury. She was discharged on DOL 12 with appropriate neurodevelopment at 2 years of age.

\section{Case 2}

A term male infant $(4.49 \mathrm{~kg})$ with an unremarkable antenatal history was delivered by vaginal delivery at $41+5$ weeks gestation with a 10 min Apgar score of 9 . The mother had hyponatraemia $(130 \mathrm{mmol} / \mathrm{L})$ 28.5 hours postpartum after drinking $10 \mathrm{~L}$ of water during labour. Arterial cord $\mathrm{pH}$ was $7.22, \mathrm{BE}-6.6$, venous $\mathrm{pH} 7.18, \mathrm{BE}-7.0$. Thick meconium was noted at delivery, but none was seen below the vocal cords. At 5 min of age, he became dusky and quiet during skin-to-skin and was moved to the NICU on nasal CPAP. He had $30 \mathrm{~s}$ of generalised limb jerking at 3 hours of age and 3 min of electro-clinical seizures at 5 hours of age. He was hyponatraemic with a sodium level of $114 \mathrm{mmol} / \mathrm{L}$ on the blood gas done at the time. He received two doses of phenobarbital $(20 \mathrm{mg} / \mathrm{kg})$ and was intubated and ventilated due to respiratory distress with worsening acidosis. Given the background of thick meconium-stained liquor, mild perinatal acidosis and seizures within 3 hours of age, the baby was offered TH. He received $2.7 \%$ $\mathrm{NaCl}$ at $3 \mathrm{~mL} / \mathrm{kg}$ and maintenance sodium infusion with serial sodium monitoring. The aEEG showed a continuous normal voltage pattern. Serum sodium normalised by 38 hours (table 1 ). Other treatments included $10 \mathrm{~mL} / \mathrm{kg} 0.9 \%$ saline bolus, inotropes at 


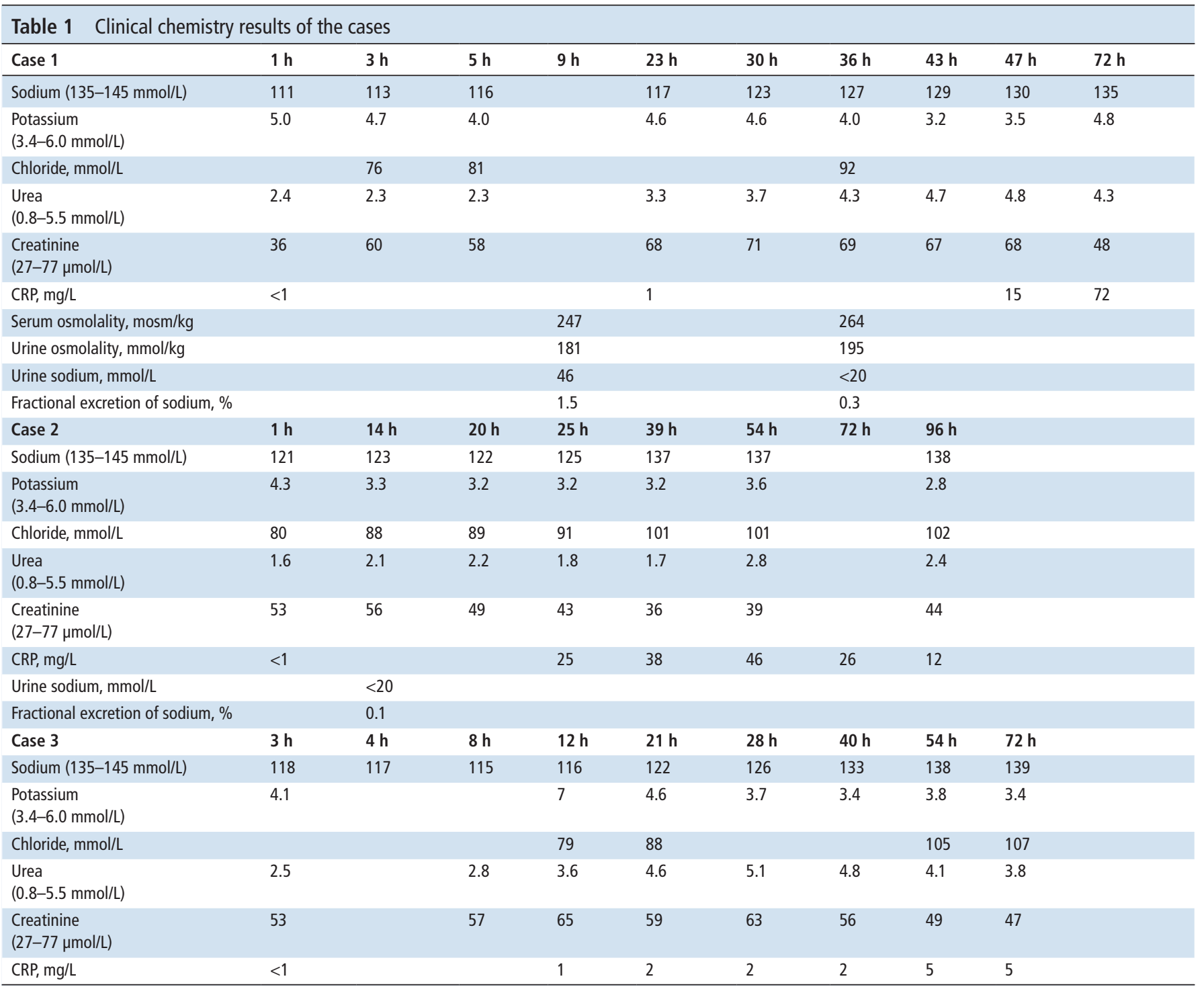

12 hours of age for rising lactate, hypotension and poor urine output, antibiotics and aciclovir for presumed infection and magnesium supplementation at 16 hours for hypomagnesaemia $(0.46 \mathrm{mmol} / \mathrm{L})$. He was extubated following rewarming on DOL 5. He did not have further seizures and his CrUSS and day 5 brain MRI were normal. Inotropes and sodium infusion were stopped by DOL 3 and 4, respectively. His blood culture, CSF viral PCR and culture were negative. He established full breastfeeding and was discharged home on DOL 8 with normal neurodevelopment at 2 years of age.

\section{Case 3}

A term infant was born via instrumental delivery under GA. The mother developed seizures in the birthing pool with post-ictal confusion and agitation necessitating GA. There was no significant medical history or risk for sepsis, but she had ingested $6 \mathrm{~L}$ of water during labour and her serum sodium was $116 \mathrm{mmol} / \mathrm{L}$. The baby was born in a poor condition requiring intubation at $6 \mathrm{~min}$ and chest compressions. Apgar score was 6 at $10 \mathrm{~min}$ with a $\mathrm{pH}$ of 7.14 on arterial cord gas. Initial venous gas showed $\mathrm{pH}$ of 6.9 , sodium 120. Due to abnormal neurology (absent suck, gag and weak grasp reflex with hypertonia in both limbs) and $\mathrm{pH}<7.0$, he was commenced on TH. At 4 hours of age, he had a repetitive twitching movement on the left foot with electrical seizures on
aEEG. The aEEG pattern was a continuous normal voltage. $\mathrm{He}$ was intubated and given phenobarbital $(20 \mathrm{mg} / \mathrm{kg})$ and a further $10 \mathrm{mg} / \mathrm{kg}$ dose on DOL 3 for seizure. Fluid was restricted to 40 $\mathrm{mL} / \mathrm{kg}$ /day with maintenance sodium infusion as serum sodium was 116. By DOL 4 he was rewarmed and extubated to air; his serum sodium had normalised (table 1) and he was fully enterally fed by DOL 6. CrUSS was normal, but a formal EEG was suggestive of moderate cerebral dysfunction but no epileptiform activity. Day 10 MRI brain showed non-haemorrhagic punctate lesions in parasagittal deep and peritrigonal cerebral white matter. His neurodevelopment at 2 years of age was normal.

\section{DIFFERENTIAL DIAGNOSIS}

Differential diagnoses for neonatal hyponatraemia include excessive maternal fluid intake in labour. Other causes include congenital adrenal hypertrophy or renal losses and syndrome of inappropriate antidiuretic hormone secretion (SIADH), which were ruled out based on normal potassium and lack of excessive sodium loss in urine. Unfortunately, our third case did not have serum or urinary osmolality to rule out SIADH. Other rare causes include congenital hypothyroidism, continuous glucagon infusion and oxytocin administration. Our cases did not have congenital hypothyroidism and did not receive glucagon. Their mothers did not receive oxytocin before giving birth. Seizures 
could occur secondary to neonatal hypoxic-ischaemic encephalopathy, meningitis and epileptic encephalopathy. Our cases had mild perinatal asphyxia and hyponatraemia, posing a clinical conundrum regarding commencing $\mathrm{TH}$ for neuroprotection.

\section{TREATMENT}

All three babies received TH as part of their treatment in addition to correction of hyponatraemia with hypertonic sodium and fluid restriction on DOL 1 to $40 \mathrm{~mL} / \mathrm{kg} /$ day. Other treatment instituted included antibiotics for presumed sepsis and shortterm anticonvulsants for seizures.

\section{OUTCOME AND FOLLOW-UP}

All our patients had resolution of their hyponatraemia and seizures prior to discharge. They were followed up until 2 years of age. They all had normal neurology and appropriate motor and cognitive development.

\section{DISCUSSION}

Seizure is a neonatal emergency and could result from dyselectrolytaemia, which accounts for $10 \%$ of cases. Seizures can occur at sodium levels $<125 \mathrm{mmol} / \mathrm{L}^{1}$

During normal pregnancy there is physiological hyponatraemia ${ }^{3}$ that can be worsened by pre-eclampsia, ${ }^{4}$ oxytocin administered in glucose solutions ${ }^{5}$ and hypotonic fluid overdose. ${ }^{6}$ Furthermore, excessive oral fluid intake can exacerbate hyponatraemia. ${ }^{78}$ While excessive fluid intake during labour has a detrimental impact on the fetal and neonatal water balance physiology, ${ }^{9}$ absolute fasting during prolonged labour may adversely impact pregnant women. ${ }^{10}$ Therefore, parturients should drink small sips of water, which need to be recorded, and modest amounts of clear isotonic drinks are recommended. ${ }^{10}$

Our cases show severe hyponatraemia from excessive maternal fluid intake in labour. All the mothers had an unremarkable antenatal history without pre-eclampsia. None of them received intravenous oxytocin or hypotonic fluids.

Other causes of early neonatal hyponatraemia such as congenital adrenal hypertrophy or renal losses and SIADH were ruled out based on normal potassium and lack of significant sodium loss in the urine. Unfortunately, our third case did not have serum or urinary osmolality to rule out SIADH.

Acute hyponatraemia results in a sudden shift of water into the brain cells causing cerebral oedema. Symptoms include apnoea or cyanotic episodes, seizures, lethargy or altered level of consciousness.

Previous case series of infants with dilutional hyponatraemia identified them from maternal symptoms or routine laboratory testing. ${ }^{11}$ While the mothers of cases 1 and 3 had clear evidence of intrapartum hyponatraemia and were symptomatic, the mother of case 2 had the first blood test at 28.5 hours postpartum which showed a sodium level of $130 \mathrm{mmol} / \mathrm{L}$. It is conceivable that this mother could have had a much lower sodium level before birth. All the infants had features of encephalopathy following mild perinatal asphyxia, but with underlying biochemical diagnoses of hyponatraemia in both mothers and infants. Although two of the infants had normal neuroimaging, the third infant had punctate white matter lesions thought to be infarcts of embolic origin, possibly from the antenatal/intrapartum period. These cases illustrate the dilemma that could arise in encephalopathic infants within the window period for instituting TH. The infants were cooled as they fulfilled criteria for cooling, yet had hyponatraemia as a treatable underlying cause.
All the infants had hyponatraemia secondary to maternal dilutional hyponatraemia, which is supported by the history of maternal excessive water intake during labour, maternal hyponatraemia and the occurrence of hyponatraemia in the babies early in the neonatal period (within 1-3 hours of birth). Hyponatraemia secondary to perinatal asphyxia occurs secondary to acute kidney injury and/or inappropriate antidiuretic hormone secretion and babies demonstrate elevated fractional excretion of sodium. ${ }^{12} \mathrm{TH}$ may worsen the asphyxia-induced hyponatraemia due to fluid overload. ${ }^{13}$ However, hyponatraemia secondary to asphyxia or TH occurs on DOL $4 .^{12} 13$ Our cases had hyponatraemia within 3 hours of birth and did not have elevated creatinine suggestive of acute kidney injury, nor did they have elevated fractional excretion of sodium as shown in table 1. While the primary problem in all our cases was neonatal hyponatraemia due to maternal dilutional hyponatraemia, they were also exposed to variable degrees of perinatal asphyxia. Cases 1 and 2 had mild degrees of asphyxia, as evidenced by acidosis in the cord blood gas and meconium-stained liquor in case 2; case 3 needed resuscitation at birth with perinatal acidosis suggesting moderate asphyxia. Encephalopathy observed in all cases could be due to hyponatraemia ${ }^{14}$ and asphyxia.

Cases 1 and 2 were delivered following administration of GA to the mothers. Excessive oral fluid intake prior to GA increases the risk of pulmonary aspiration. Additionally, stress and some anaesthetic drugs may increase ADH secretion, worsening hyponatraemia. ${ }^{15}$ Both neonates had acidosis in the cord blood indicating that hypoxia had occurred prior to birth and therefore the influence of GA on the perinatal clinical presentation is likely to be non-existent.

$\mathrm{TH}$ has been used in infants who do not fulfil the standard criteria of hypoxic ischaemic encephalopathy with good outcome except in cases of major intracranial haemorrhage. ${ }^{16}$ To our knowledge, this is the first report of cooling in infants with perinatal asphyxial encephalopathy and severe hyponatraemic seizures. We did not observe any adverse effects and the longterm neurodevelopment outcome was reassuring. It is essential that maternity healthcare providers and pregnant women are aware of the adverse effects of consuming large volumes of water for pain relief.

\section{Learning points}

Neonatal hyponatraemia can occur following mothers drinking large volumes of water in labour.

- Hyponatraemia could result in encephalopathic features such as seizures in the newborn.

- Encephalopathy occurring in the setting of mild perinatal asphyxia and hyponatraemia poses decision-making challenges in instituting therapeutic hypothermia.

- Therapeutic hypothermia and hyponatraemia correction in infants with encephalopathy following hyponatraemia and perinatal asphyxia may prevent adverse neurodevelopment.

- During labour, pregnant women should be made aware of the risks of excessive water intake and encouraged to drink small sips of water that are recorded and favouring isotonic drinks.

Contributors EC is a senior lecturer with the University of Bristol and a neonatologist at the St Michael's Hospital and supervised this case series. He is also the corresponding author and wrote the final version of the manuscript. OA summarised two of the cases and obtained verbal consent from the parents for the reports. RR summarised one of the cases and obtained the written parental consents. $\mathrm{AJ}$ is a neonatal consultant at St Michael's Hospital; he reviewed the articles and is the consultant for one of the babies. 
Funding The authors have not declared a specific grant for this research from any funding agency in the public, commercial or not-for-profit sectors.

Competing interests None declared.

Patient consent for publication Obtained.

Provenance and peer review Not commissioned; externally peer reviewed.

\section{ORCID iD}

Ela Chakkarapani http://orcid.org/0000-0003-3380-047X

\section{REFERENCES}

1 Tekgul H, Gauvreau K, Soul J, et al. The current etiologic profile and neurodevelopmental outcome of seizures in term newborn infants. Pediatrics 2006;117:1270-80.

2 Ophir E, Solt I, Odeh M, et al. Water intoxication-a dangerous condition in labor and delivery rooms. Obstet Gynecol Surv 2007;62:731-8.

3 Pazhayattil GS, Rastegar A, Brewster UC. Approach to the diagnosis and treatment of hyponatremia in pregnancy. Am J Kidney Dis 2015;65:623-7.

4 Powel JE, Rosenthal E, Roman A, et al. Preeclampsia and low sodium (PalS): a case and systematic review. Eur J Obstet Gynecol Reprod Biol 2020;249:14-20.

5 Stratton JF, Stronge J, Boylan PC. Hyponatraemia and non-electrolyte solutions in labouring primigravida. Eur J Obstet Gynecol Reprod Biol 1995;59:149-51.
6 Burt RL, Oliver KL, Whitener DL. Water intoxication complicating elective induction of labor at term. Report of a patient who survived. Obstet Gynecol 1969;34:212-4.

7 Johansson S, Lindow S, Kapadia H, et al. Perinatal water intoxication due to excessive oral intake during labour. Acta Paediatr 2002;91:811-4.

8 Moen V, Brudin L, Rundgren M, et al. Hyponatremia complicating labour--rare or unrecognised? A prospective observational study. BJOG 2009;116:552-61.

9 Lindower JB. Water balance in the fetus and neonate. Semin Fetal Neonatal Med 2017:22:71-5.

10 Maharaj D. Eating and drinking in labor: should it be allowed? Eur J Obstet Gynecol Reprod Biol 2009;146:3-7.

11 Solomon N, Many A, Orbach R, et al. Maternal and neonatal hyponatremia during labor: a case series. J Matern Fetal Neonatal Med 2019;32:2711-5.

12 Aggarwal A, Kumar P, Chowdhary G, et al. Evaluation of renal functions in asphyxiated newborns. J Trop Pediatr 2005;51:295-9.

13 Prempunpong C, Efanov I, Sant'anna G. The effect of the implementation of therapeutic hypothermia on fluid balance and incidence of hyponatremia in neonates with moderate or severe hypoxic-ischaemic encephalopathy. Acta Paediatr 2013;102:n/a-513.

14 Asaki Y, Murofushi Y, Yasukawa K, et al. Neurochemistry of hyponatremic encephalopathy evaluated by MR spectroscopy. Brain Dev 2020;42:767-70.

15 Burchardi $H$, Kaczmarczyk $G$. The effect of anaesthesia on renal function. Eur J Anaesthesiol 1994;11:163-8.

16 Smit E, Liu X, Jary S, et al. Cooling neonates who do not fulfil the standard cooling criteria - short- and long-term outcomes. Acta Paediatr 2015;104:138-45.

Copyright 2021 BMJ Publishing Group. All rights reserved. For permission to reuse any of this content visit

https://www.bmj.com/company/products-services/rights-and-licensing/permissions/

BMJ Case Report Fellows may re-use this article for personal use and teaching without any further permission.

Become a Fellow of BMJ Case Reports today and you can:

- Submit as many cases as you like

- Enjoy fast sympathetic peer review and rapid publication of accepted articles

- Access all the published articles

Re-use any of the published material for personal use and teaching without further permission

Customer Service

If you have any further queries about your subscription, please contact our customer services team on +44 (0) 2071111105 or via email at support@bmj.com.

Visit casereports.bmj.com for more articles like this and to become a Fellow 